\title{
Correlation between non-invasive myocardial work indices and main parameters of systolic and diastolic function: results from the EACVI NORRE study
}

Roberta Manganaro', Stella Marchetta ${ }^{1}$, Raluca Dulgheru', Tadafumi Sugimoto ${ }^{1,2}$, Toshimitsu Tsugu ${ }^{1,3}$, Federica Ilardi ${ }^{1,4}$, Marianna Cicenia ${ }^{1}$, Arnaud Ancion ${ }^{1}$, Adriana Postolache ${ }^{1}$, Christophe Martinez ${ }^{1}$, George Kacharava ${ }^{5}$, George D. Athanassopoulos ${ }^{6}$, Daniele Barone ${ }^{7}$, Monica Baroni ${ }^{8}$, Nuno Cardim ${ }^{9}$, Andreas Hagendorff ${ }^{10}$, Krasimira Hristova ${ }^{11}$, Teresa Lopez ${ }^{12}$, Gonzalo de la Morena ${ }^{13}$, Bogdan A. Popescu ${ }^{14}$, Martin Penicka ${ }^{15}$, Tolga Ozyigit ${ }^{16}$, Jose David Rodrigo Carbonero ${ }^{17}$, Nico van de Veire ${ }^{18}$, Ralph Stephan Von Bardeleben ${ }^{19}$, Dragos Vinereanu ${ }^{20}$, Jose Luis Zamorano ${ }^{21}$, Monica Rosca ${ }^{14}$, Andreea Calin ${ }^{14}$, Marie Moonen ${ }^{1}$, Julien Magne ${ }^{22,23}$, Bernard Cosyns $^{24}$, Elena Galli ${ }^{25}$, Erwan Donal ${ }^{25}$, Scipione Carerj ${ }^{26}$, Concetta Zito ${ }^{26}$, Ciro Santoro ${ }^{4}$, Maurizio Galderisi ${ }^{4}$, Luigi P. Badano ${ }^{27}$, Roberto M. Lang ${ }^{28}$, and Patrizio Lancellotti ${ }^{1,29 *}$

\footnotetext{
${ }^{1}$ Department of Cardiology, University of Liège Hospital, GIGA Cardiovascular Sciences, Heart Valve Clinic, CHU du Sart Tilman, Domaine Universitaire du Sart Tilman, Batiment B35, 4000 Liège, Belgium; ${ }^{2}$ Department of Clinical Laboratory, Mie University Hospital, Mie, 2-174 Edobashi, $514-8507$ Tsu, Japan; ${ }^{3}$ Department of Cardiology, School of Medicine, Keio University, 160-8582 Tokyo, Japan; ${ }^{4}$ Department of Advanced Biomedical Sciences, Federico II University Hospital, Via S.Pansini, 5, 80131 Napoli, Italy; ${ }^{5}$ Department of Cardiology, Tbilisi Institute of Medicine (TIM), 16 Tsintsadze, 0160 Tbilisi, Georgia; ${ }^{6}$ Noninvasive Diagnostics Department, Onassis Cardiac Surgery Center, Leof. Andrea Siggrou 356, 17674 Kallithea, Athens, Greece; ${ }^{7}$ Cardiology Department, Laboratory of Cardiovascular Ecography, S. Andrea Hospital, La Spezia, Italy; ${ }^{8}$ Laboratorio Di Ecocardiografia Adulti, Fondazione Toscana “G.Monasterio” - Ospedale Del Cuore, Via Giuseppe Moruzzi, 1, 56124 Pisa, Massa, Italy; ${ }^{2}$ Echocardiography Laboratory, Hospital da Luz, Av. Lusíada 100, 1500-650 Lisboa, Portugal; ${ }^{10}$ Department of Cardiology, University of Leipzig, Liebigstraße 20, 04103 Leipzig, Germany; ${ }^{11}$ Department of Noninvasive Functional Diagnostic and Imaging, University National Heart Hospital, ul. 'Konyovitsa' 65, 1309 g.k. Ilinden, Sofia, Bulgaria; ${ }^{12}$ Cardiology Department, La Paz Hospital, Paseo de la Castellana, 261, 28046 Madrid, Spain; ${ }^{13}$ Unidad de Imagen Cardiaca, Servicio de Cardiologia, Hospital Clinico Universitario Virgen de la Arrixaca, IMIB-Arrixaca, Ctra. MadridCartagena, s/n, 30120 El Palmar, Murcia, Spain; ${ }^{14}$ Department of Cardiology, University of Medicine and Pharmacy 'Carol Davila', Euroecolab, Institute of Cardiovascular Diseases 'Prof. Dr. C. C. Iliescu', Sos. Fundeni 258, sector 2, 022328 Bucharest, Romania; ${ }^{15}$ Cardiovascular Center Aalst, OLV-Clinic, Moorselbaan 164,9300 Aalst, Belgium; ${ }^{16}$ VKV Amerikan Hastanesi, Kardiyoloji Bölümü, Tes yikiye, Güzelbahçe Sok, No: 20, 34365 Nişantaşı Istanbul Turkey; ${ }^{17}$ Laboratorio de Ecocardiografia Hospital de Cruces, Plaza de Cruces, S/N, 48903 Baracaldo, Vizcaya, Spain; ${ }^{18}$ Echocardiography Unit, AZ Maria Middelares Gent, Buitenring-Sint-Denijs 30, 9000 Gent, Belgium; ${ }^{19}$ Medical Department Cardiology, Universitätsmedizin of the Johannes Gutenberg-University Mainz, Langenbeckstraße 1, 55131 Mainz, Germany; ${ }^{20}$ Cardiovascular Research Unit, University and Emergency Hospital, University of Medicine and Pharmacy Carol Davila, Sector 1, Strada Dionisie Lupu 37, 030167 Bucureşti, Romania; ${ }^{21}$ University Alcala, Hospital Ramón y Cajal, Ctra. De Colmenar Viejo, km. 9, 100, 28034 Madrid, Spain; ${ }^{22}$ CHU Limoges, Hôpital Dupuytren, Service Cardiologie, Limoges F-87042, France; ${ }^{23}$ INSERM 1094, Faculté de médecine de Limoges, 2, rue Marcland, 87000 Limoges, France; ${ }^{24} \mathrm{CHVZ} \mathrm{(Centrum} \mathrm{voor} \mathrm{Hart} \mathrm{en} \mathrm{Vaatziekten),} \mathrm{Universitair} \mathrm{ziekenhuis} \mathrm{Brussel} \mathrm{and} \mathrm{ICMI} \mathrm{(In} \mathrm{Vivo} \mathrm{Cellular} \mathrm{and}$ Molecular Imaging) Laboratory, Avenue du Laerbeek 101, 1090 Jette, Brussels, Belgium; ${ }^{25} \mathrm{CIC}-\mathrm{IT} \cup 1414$, CHU Rennes, Université Rennes 1 , Service de Cardiologie, CHU Rennes, 2 Rue Henri le Guilloux, 35000 Rennes, France; ${ }^{26}$ Department of Clinical and Experimental Medicine, Section of Cardiology, University of Messina, 1, Via Consolare Valeria - 98125 Messina (IT), Italy; ${ }^{27}$ Department of Medicine and Surgery, University Milano-Bicocca, and Istituto Auxologico Italiano, IRCCS, Cardiology Unit and Dept of Cardiovascular, Neural and Metabolic Sciences, San Luca Hospital, P.le Brescia 20, 20149 Milano, Italy; ${ }^{28}$ Department of Medicine, University of Chicago Medical Center, 5841 S Maryland Ave, Chicago, 60637 IL, USA; and ${ }^{29}$ Gruppo Villa Maria Care and Research, Anthea Hospital, Via Camillo Rosalba, 35,70124 Bari, Italy
} 
Aims

The present study sought to evaluate the correlation between indices of non-invasive myocardial work (MW) and left ventricle (LV) size, traditional and advanced parameters of LV systolic and diastolic function by 2D echocardiography (2DE).

Methods

and results

A total of 226 ( 85 men, mean age: $45 \pm 13$ years) healthy subjects were enrolled at 22 collaborating institutions of the Normal Reference Ranges for Echocardiography (NORRE) study. Global work index (GWI), global constructive work (GCW), global work waste (GWW), and global work efficiency (GWE) were estimated from LV pressure-strain loops using custom software. Peak LV pressure was estimated non-invasively from brachial artery cuff pressure. LV size, parameters of systolic and diastolic function and ventricular-arterial coupling were measured by echocardiography. As advanced indices of myocardial performance, global longitudinal strain (GLS), global circumferential strain (GCS), and global radial strain (GRS) were obtained. On multivariable analysis, GWI was significantly correlated with GLS (standardized beta-coefficient $=-0.23, P<0.001$ ), ejection fraction (EF) (standardized beta-coefficient $=0.15, P=0.02$ ), systolic blood pressure (SBP) (standardized beta-coefficient $=0.56, P<0.001$ ) and GRS (standardized beta-coefficient $=0.19, P=0.004$ ), while GCW was correlated with GLS (standardized beta-coefficient $=-0.55, P<0.001$ ), SBP (standardized beta-coefficient $=0.71, P<0.001$ ), GRS (standardized beta-coefficient $=0.11, P=0.02$ ), and GCS (standardized beta-coefficient $=-0.10, P=0.01$ ). GWE was directly correlated with EF and inversely correlated with Tei index (standardized betacoefficient $=0.18, P=0.009$ and standardized beta-coefficient $=-0.20, P=0.004$, respectively), the opposite occurred for GWW (standardized beta-coefficient $=--0.14, P=0.03$ and standardized beta-coefficient $=0.17, P=0.01$, respectively).

Conclusion $\quad$ The non-invasive MW indices show a good correlation with tra......................................................................... tion and myocardial strain.

Keywords adult echocardiography $\bullet$ speckle tracking echocardiography $\bullet$ myocardial work • myocardial strain

\section{Introduction}

Myocardial deformation analysis, by tissue Doppler imaging (TDI) and/or speckle tracking echocardiography (STE), developed in the last decade as a reliable tool for assessing left ventricle (LV) systolic function. In addition to traditional parameters, such as ejection fraction (EF), ${ }^{1,2}$ myocardial strain (MS) allows the detection of early subclinical LV dysfunction in a variety of cardiac diseases. ${ }^{3-9}$ However, its relative load-dependency makes it unable for MS to account for changes in pre- and afterload. Recently, non-invasive myocardial work (MW) was proposed as a new tool to study LV performance, which takes into account myocardial deformation and afterload. Russell et al., ${ }^{10}$ indeed, developed a non-invasive method to calculate MW using LV pressure-strain loops (PSLs) obtained from STE. These authors demonstrated that regional differences in $\mathrm{MW}$ assessed by PSLs have a strong correlation with myocardial glucose metabolism as evaluated with fluorodeoxyglucose positron emission tomography. The application of these concepts to myocardial ischaemia and the assessment of cardiac resynchronization therapy (CRT)-responders have been evaluated, showing good results. ${ }^{11-17}$

The NORRE (Normal Reference Ranges for Echocardiography) study is the first European, large, prospective, multicentre study performed in 22 laboratories accredited by the European Association of Cardiovascular Imaging (EACVI) and in one American laboratory, which has provided reference values for all $2 \mathrm{D}$ echocardiographic (2DE) measurements of the four cardiac chambers, ${ }^{18}$ Doppler parameters, ${ }^{19}$ aortic dimensions, ${ }^{20} 3 \mathrm{D}$ echocardiographic measurements of LV volumes and strain, ${ }^{21} 2 D E$ measurement of $L V$ strains and twist, ${ }^{22} 2 \mathrm{D}$ and 3D measurement of left atrial function, ${ }^{23}$ and, more recently, 2D measurement of $\mathrm{MW}$ indices. ${ }^{24}$ The present study aimed to evaluate the correlation between indices of non-invasive MW and LV size, traditional and advanced parameters of LV systolic and indices of diastolic function by $2 \mathrm{DE}$.

\section{Methods}

\section{Patient population}

A total of 734 healthy European subjects constituted the final NORRE study population. The local ethics committees approved the study protocol. Since GE echocardiographic system is the only equipped with a software package to calculate MW, only patients scanned with this system $(n=378)$ were included. After the exclusion of patients that had incompatible image format and/or poor-image quality and/or whose blood pressure at the time of echocardiographic examination was not available, the final study population consisted of 226 (31\% of the total NORRE population, $58 \%$ of all patients scanned with GE ultrasound system) normal subjects. All the 23 laboratories involved in the NORRE studies contributed to the final population.

\section{Echocardiographic examination}

A comprehensive echocardiographic examination was performed using a state-of-the-art echocardiographic ultrasound system (GE Vivid E9; Vingmed Ultrasound, Horten, Norway) following recommended protocols approved by the EACVI. ${ }^{25,26}$ All echocardiographic images were recorded in a digital raw-data format (native DICOM format) and centralized for further analysis, after anonymization, at the EACVI Central Core Laboratory at the University of Liege, Belgium.

LV end-diastolic and end-systolic volumes (EDV and ESV, respectively) were measured and indexed to body surface area (BSA), and EF was calculated using biplane Simpson's method. ${ }^{27} \mathrm{LV}$ mass was calculated from linear measurements obtained from parasternal views and indexed to BSA. Mitral annular plane systolic excursion was measured by the use of M-mode echocardiography in an apical view at the septal and lateral mitral annuli.

The left ventricle outflow tract (LVOT) diameter was measured at the aortic valve annulus, $0.5-1 \mathrm{~cm}$ below the aortic cups from a zoomed parasternal long-axis acoustic window. LVOT velocity-time integral was measured in the apical five-chamber view using pulsed-wave Doppler just proximal to the aortic valve. Stroke volume (SV) by Doppler (LVOT area 
Table I Standard and advanced echocardiographic characteristics of study population

\begin{tabular}{|c|c|c|c|c|}
\hline & $\begin{array}{l}\text { Total }(n=226) \\
\text { mean } \pm \text { SD or } \\
\text { medial }(\text { IQR) }\end{array}$ & $\begin{array}{l}\text { Male }(n=85) \\
\text { mean } \pm \text { SD or } \\
\text { medial }(\text { IQR) }\end{array}$ & $\begin{array}{l}\text { Female }(n=141) \\
\text { mean } \pm \text { SD or } \\
\text { medial }(I Q R)\end{array}$ & $P$-value ${ }^{a}$ \\
\hline $\operatorname{LVEDV~}(\mathrm{mL})$ & $93 \pm 24$ & $107 \pm 25$ & $84 \pm 19$ & $<0.001$ \\
\hline LVESV (mL) & $34 \pm 10$ & $39 \pm 11$ & $31 \pm 8$ & $<0.001$ \\
\hline $\operatorname{LVEDV}\left(\mathrm{mL} / \mathrm{m}^{2}\right)$ & $52 \pm 11$ & $55 \pm 12$ & $50 \pm 10$ & 0.002 \\
\hline $\operatorname{LVESV}\left(\mathrm{mL} / \mathrm{m}^{2}\right)$ & $19 \pm 5$ & $20 \pm 5$ & $19 \pm 5$ & 0.02 \\
\hline LVEF (\%) & $63 \pm 5$ & $63 \pm 5$ & $63 \pm 5$ & 0.6 \\
\hline LV mass indexed $\left(\mathrm{g} / \mathrm{m}^{2}\right)$ & $71 \pm 17$ & $76 \pm 16$ & $67 \pm 16$ & $<0.001$ \\
\hline $\mathrm{SV}$ indexed $\left(\mathrm{mL} / \mathrm{m}^{2}\right)$ & $39(35-44)$ & $40(36-47)$ & $38(34-43)$ & 0.03 \\
\hline $\mathrm{CO}(\mathrm{mL} / \mathrm{min})$ & $4.6(3.9-5.3)$ & $4.9(4.3-5.9)$ & $4.4(3.8-5.1)$ & $<0.001$ \\
\hline $\mathrm{Cl}\left(\mathrm{mL} / \mathrm{min} / \mathrm{m}^{2}\right)$ & $2.6 \pm 0.5$ & $2.6 \pm 0.6$ & $2.7 \pm 0.6$ & 0.5 \\
\hline Septal MAPSE (mm) & $15(14-17)$ & $16(15-17.7)$ & $15(14-18)$ & $<0.001$ \\
\hline Lateral MAPSE (mm) & $17(15-18)$ & $17(15.2-19)$ & $16(15-19)$ & 0.004 \\
\hline Septal s' wave (m/s) & $8(7-9)$ & $8(8-10)$ & $8(7-8)$ & $<0.001$ \\
\hline Lateral s' wave (m/s) & $10(8-12)$ & $11(9-12)$ & $9(8-11)$ & 0.002 \\
\hline $\mathrm{LAV}(\mathrm{mL})$ & $45.1(38.3-54.7)$ & $50.5(42.9-59)$ & $42.4(36.5-50)$ & $<0.001$ \\
\hline LAV indexed $\left(\mathrm{mL} / \mathrm{m}^{2}\right)$ & $25.4(22-30.1)$ & $25.4(22.3-30.5)$ & $25.4(21.8-29.9)$ & 0.7 \\
\hline E wave $(\mathrm{cm} / \mathrm{s})$ & $0.76 \pm 0.16$ & $0.72 \pm 0.16$ & $0.79 \pm 0.16$ & 0.003 \\
\hline A wave $(\mathrm{cm} / \mathrm{s})$ & $0.58(0.48-0.68)$ & $0.55(0.46-0.58)$ & $0.59(0.50-0.68)$ & 0.09 \\
\hline Deceleration time (ms) & 173 (159-202) & $180(160-210)$ & $172(157-198)$ & 0.2 \\
\hline E/A ratio & $1.3(1-1.6)$ & $1.3(0.99-1.6)$ & $1.3(1-1.6)$ & 0.5 \\
\hline Septal e' wave $(\mathrm{m} / \mathrm{s})$ & $10(9-12)$ & $10(9-12)$ & $10(9-12)$ & 0.9 \\
\hline Lateral e' wave $(\mathrm{m} / \mathrm{s})$ & $14(11-16)$ & $14(11-17)$ & $14(11-16)$ & 0.3 \\
\hline E/e' ratio & $6.2(5.3-7.6)$ & $5.8(5-6.9)$ & $6.5(5.7-7.9)$ & 0.001 \\
\hline PASP $(\mathrm{mmHg})$ & $18 \pm 5$ & $17.5 \pm 5.2$ & $18.6 \pm 4.9$ & 0.2 \\
\hline Tei index & $0.45(0.39-0.51)$ & $0.47(0.42-0.55)$ & $0.42(0.38-0.49)$ & $<0.001$ \\
\hline $\mathrm{Ea}(\mathrm{mmH} / \mathrm{mL})$ & $1.4(1.3-1.7)$ & $1.4(1.2-1.5)$ & $1.5(1.3-1.8)$ & $<0.001$ \\
\hline Ees $(\mathrm{mmH} / \mathrm{mL})$ & $1.5(1.3-1.8)$ & $1.5(1.3-1.6)$ & $1.6(1.4-1.9)$ & $<0.001$ \\
\hline Ea/Ees & $0.94(0.93-0.94)$ & $0.94(0.93-0.94)$ & $0.93(0.93-0.94)$ & 0.03 \\
\hline GLS (\%) & $-21 \pm 3.3$ & $-20.5 \pm 1.9$ & $-21.3 \pm 3.9$ & 0.08 \\
\hline GCS (\%) & $-32.7 \pm 4.5$ & $-33.1 \pm 5.1$ & $-32.4 \pm 4$ & 0.3 \\
\hline GRS (\%) & $34.1 \pm 8.8$ & $33 \pm 9.7$ & $35 \pm 8.1$ & 0.1 \\
\hline $\mathrm{GWI}(\mathrm{mmHg} \%)$ & $1896 \pm 308$ & $1849 \pm 295$ & $1924 \pm 313$ & 0.07 \\
\hline $\mathrm{GCW}(\mathrm{mmHg} \%)$ & $2232 \pm 331$ & $2228 \pm 295$ & $2234 \pm 352$ & 0.9 \\
\hline GWW (mmHg\%) & $78.5(53-122.2)$ & $94(61.5-130.5)$ & $74(49.5-111)$ & 0.013 \\
\hline GWE (mmHg\%) & 96 (94-97) & 95 (94-97) & 96 (94-97) & 0.026 \\
\hline
\end{tabular}

$\times$ LVOT velocity-time integral), cardiac output $(\mathrm{CO})(\mathrm{SV} \times$ heart rate), and cardiac index $(\mathrm{Cl})(\mathrm{CO} / \mathrm{BSA})$ were calculated. Transmitral flow pattern with $E$ and $A$ wave velocities was obtained with the sample volume positioned at mitral leaflet tips. Systolic (s') and early diastolic mitral annular velocity (e'), at both the septal and lateral side, were obtained using pulse wave (PW) TDI; moreover, isovolumetric contraction time (IVCT), isovolumetric relaxation time (IVRT), and ejection time (ET) were measured by PW TDI in order to calculate the Tei index. ${ }^{28}$ Biplane left atrial volume (LAV) was calculated using Simpson's biplane method and indexed to BSA. Arterial elastance (Ea) and end-systolic elastance (Ees) were calculated according to Chen et al. ${ }^{29}$; subsequently, Ea/Ees ratio was obtained and used as an index of ventricular-arterial coupling (VAC).

\section{D LV strain and MW analysis}

Quantification of 2D strain was performed using commercially available software (Echopac V.202, GE). Analysis was performed in all three apical views (LV four-, two-, and three-chamber views) as well as three shortaxis views (LV basal, mid, and apical views). The reference point was set at the onset of the QRS complex. End-systole was identified as the time in which the LV cavity was the smallest. The endocardial border was 
Table 2 Univariable and multivariable analysis for GWI

\begin{tabular}{|c|c|c|c|c|}
\hline \multirow[t]{2}{*}{ Variables } & \multicolumn{2}{|l|}{$\begin{array}{l}\text { Univariable } \\
\text { analysis }\end{array}$} & \multicolumn{2}{|l|}{$\begin{array}{l}\text { Multivariable } \\
\text { analysis }\end{array}$} \\
\hline & Coefficient & $P$ & $\begin{array}{l}\text { Standardized } \\
\beta \text {-coefficient }\end{array}$ & $P$ \\
\hline $\mathrm{SBP}(\mathrm{mmHg})$ & 0.57 & $<0.001$ & 0.56 & $<0.001$ \\
\hline $\mathrm{EDV}(\mathrm{mL})$ & 0.09 & 0.1 & & \\
\hline $\mathrm{ESV}(\mathrm{mL})$ & -0.07 & 0.2 & & \\
\hline EDV indexed $\left(\mathrm{mL} / \mathrm{m}^{2}\right)$ & 0.11 & 0.1 & & \\
\hline ESV indexed $\left(\mathrm{mL} / \mathrm{m}^{2}\right)$ & -0.08 & 0.2 & & \\
\hline $\mathrm{EF}(\%)$ & 0.32 & $<0.001$ & 0.15 & 0.02 \\
\hline LV mass indexed $\left(\mathrm{g} / \mathrm{m}^{2}\right)$ & 0.15 & 0.02 & & \\
\hline SV indexed $\left(\mathrm{mL} / \mathrm{m}^{2}\right)$ & 0.26 & $<0.001$ & & \\
\hline $\mathrm{CO}(\mathrm{mL} / \mathrm{min})$ & 0.14 & 0.03 & & \\
\hline $\mathrm{Cl}\left(\mathrm{mL} / \mathrm{min} / \mathrm{m}^{2}\right)$ & 0.19 & 0.004 & & \\
\hline Septal MAPSE (mm) & -0.012 & 0.7 & & \\
\hline Lateral MAPSE (mm) & -0.015 & 0.8 & & \\
\hline Septal s' wave $(\mathrm{cm} / \mathrm{s})$ & -0.06 & 0.3 & & \\
\hline Lateral s' wave (cm/s) & -0.13 & 0.04 & & \\
\hline $\mathrm{LAV}(\mathrm{mL})$ & 0.12 & 0.08 & & \\
\hline LAV indexed $\left(\mathrm{mL} / \mathrm{m}^{2}\right)$ & 0.19 & 0.006 & & \\
\hline E wave $(\mathrm{cm} / \mathrm{s})$ & 0.12 & 0.07 & & \\
\hline A wave $(\mathrm{cm} / \mathrm{s})$ & 0.17 & 0.009 & & \\
\hline Deceleration time (ms) & -0.05 & 0.3 & & \\
\hline E/A ratio & -0.06 & 0.3 & & \\
\hline Septal e' wave $(\mathrm{cm} / \mathrm{s})$ & -0.13 & 0.05 & & \\
\hline Lateral e' wave (cm/s) & -0.03 & 0.05 & & \\
\hline E/e' ratio & 0.23 & 0.001 & & \\
\hline PASP $(\mathrm{mmH} \mathrm{g})$ & 0.06 & 0.4 & & \\
\hline Tei index & -0.07 & 0.2 & & \\
\hline $\mathrm{Ea}(\mathrm{mmH} / \mathrm{gL})$ & 0.08 & 0.2 & & \\
\hline Ees $(\mathrm{mmH} / \mathrm{mL})$ & 0.09 & 0.1 & & \\
\hline $\mathrm{Ea} /$ Ees & 0.29 & $<0.001$ & & \\
\hline GLS (\%) & -0.51 & $<0.001$ & -0.23 & $<0.001$ \\
\hline GCS (\%) & -0.15 & 0.05 & & \\
\hline GRS (\%) & 0.22 & 0.006 & 0.19 & 0.004 \\
\hline
\end{tabular}

$P$-values $<0.05$ are set in bold.

$\mathrm{Cl}$, cardiac index; $\mathrm{CO}$, cardiac output; Ea, arterial elastance; EDV, end-diastolic volume; Ees, end-systolic elastance; EF, ejection fraction; ESV, end-systolic volume; GCS, global circumferential strain; GCW, global constructive work; GLS, global longitudinal strain; GRS, global radial strain; GWE, global work efficiency; GWI, global work index; GWW, global work waste; IQR, interquartile range; LAV, left atrial volume; LV, left ventricle; MAPSE, mitral annular plane systolic excursion; PASP, pulmonary arterial systolic pressure; SD, standard deviation; SBP, systolic blood pressure; SV, stroke volume.

traced in end-systole and the region of interest was adjusted to exclude the pericardium by attentively aligning the epicardial border. The integrity of tracking was visually confirmed as well as ascertained from the credibility of the strain curves, in addition to the automated tracking detection in the software. If necessary, the region of interest was readjusted. Peak systolic circumferential and peak systolic radial strain were measured at the basal, midventricular, and apical levels in each wall and averaged into a global value for each short-axis level and type of strain.

MW was obtained using a vendor-specific module by PSLs areas, which were constructed from non-invasive LV pressure (LVP) curves combined with strain acquired with STE, as previously reported. ${ }^{10,24}$ Peak systolic LVP was assumed to be equal to brachial systolic blood pressure (SBP) measured by cuff manometer. Therefore, a LVP curve was obtained using an empiric, normalized reference curve that was adjusted according to the duration of the LV isovolumetric and ejection phases, defined by the mitral and aortic event times, as set by echocardiography.

Strain and pressure data were synchronized by aligning the valvular event times. Global work index (GWI) was obtained as total work within the area of the LV PSLs, calculated from mitral valve closure to mitral valve opening. Moreover, additional indices of $\mathrm{MW}$ were calculated as follows: global constructive work (GCW), work performed during shortening in systole adding negative work during lengthening in isovolumetric relaxation; global wasted work (GWW), negative work performed during lengthening in systole adding work performed during shortening in isovolumetric relaxation; global work efficiency (GWE), constructive work divided by the sum of constructive and wasted work.

\section{Statistical analysis}

Normality of the distribution of continuous variables was tested by the Kolmogorov-Smirnov test. Continuous variables were expressed as means \pm standard deviation (SD) or median (interquartile range) as appropriate. Differences between groups were analysed for statistical significance with the unpaired $t$-test for normally distributed continuous variables and the Mann-Whitney $U$ test for non-normally distributed continuous variables. Correlation between continuous variables was performed using Pearson's or Spearman's correlation coefficient as appropriate. Multivariable linear regression analyses were performed to examine the independent correlates between MW indices and standard and advanced echocardiographic parameters. For multiple linear regression models, multicollinearity was also examined by computation of variance inflation factor. In case of collinear variables, the variable with the highest correlation coefficient was included. $P$-value $<0.05$ was considered as statistically significant. All statistical analyses were carried out using SPSS version 21 (SPSS Inc., Chicago, IL, USA).

\section{Results}

A total of 85 men (mean age $45 \pm 14$ years) and 141 women (mean age $44 \pm 13$ years) were included. Other demographic data of the population analysed in the present study were previously reported. ${ }^{24}$ Standard and advanced 2DE parameters of the study population are displayed in Table 1. LV mass and volumes were greater in men compared with women, even after normalization for BSA; the same was observed for SV, CO, and $\mathrm{Cl}$. No significant differences were found for EF and all average strain components. Indices of VAC were slightly higher in women.

\section{Correlations between GWI and 2DE parameters}

As expected, GWI showed a good correlation with SBP and global longitudinal strain (GLS) $(r=0.57, P<0.0001$ and $r=-0.51, P<0.001$, respectively), a moderate correlation with $\mathrm{EF}$ and $\mathrm{Ea} / \mathrm{Ees}(r=0.32$, $P<0.001$ and $r=0.29, P<0.001)$ and a weak correlation with LV mass indexed to BSA, SV indexed to BSA, CO, Cl, lateral s' wave, E/e' ratio and global radial strain (GRS) (Table 2). On multivariable analysis, GWI was significantly correlated with GLS (standardized betacoefficient $=-0.23, \quad P<0.001), \quad E F \quad$ (standardized beta-coefficient $=0.15, P=0.02$ ), SBP (standardized beta-coefficient $=0.56$ 

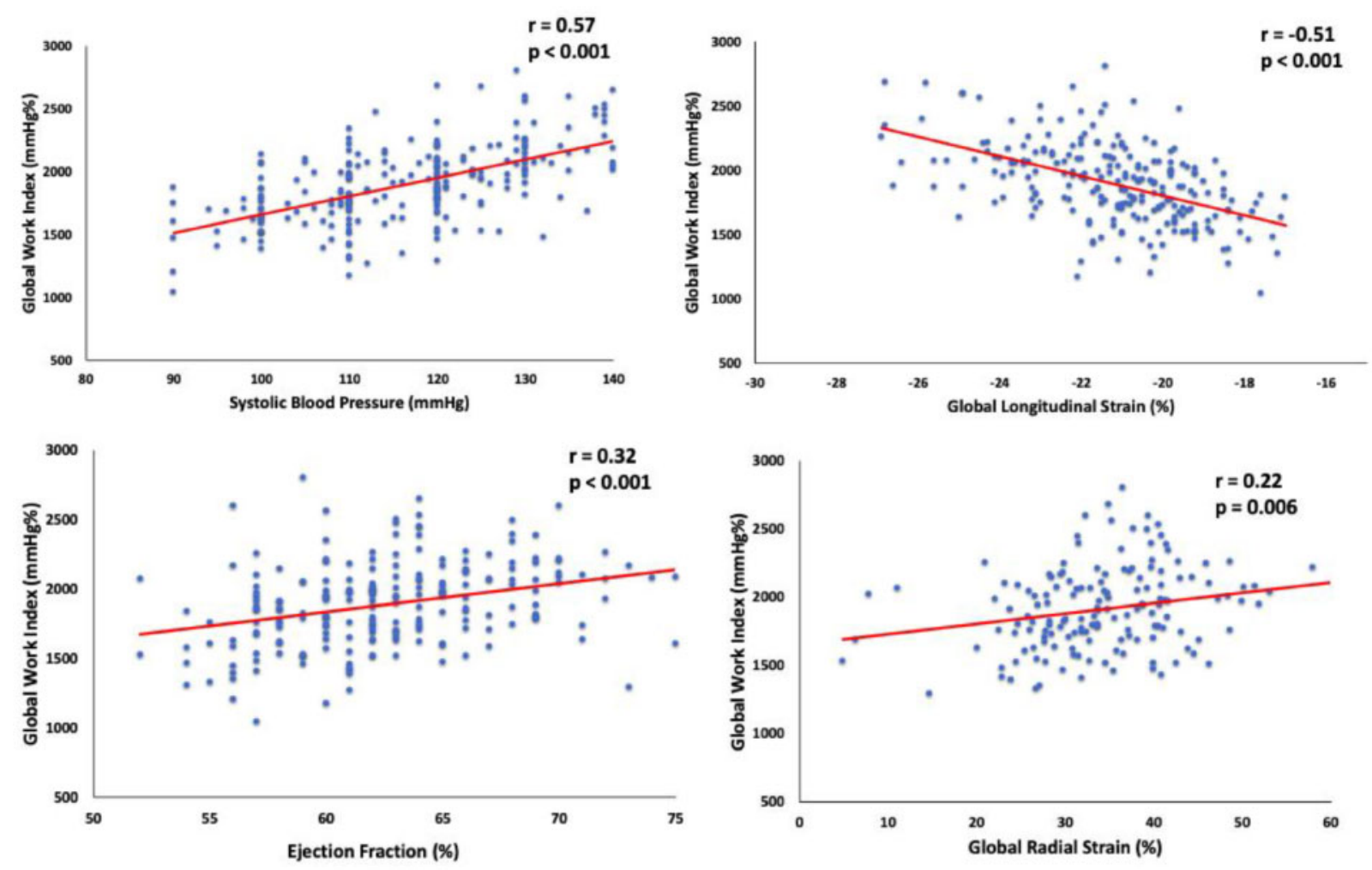

Figure I Main relations of global work index.

$P<0.001$ ) and GRS (standardized beta-coefficient $=0.19, P=0.004$ ) (Figure 1 and Table 2).

\section{Correlations between GCW and 2DE parameters}

GCW showed a good correlation with SBP and GLS $(r=0.64$, $P<0.001$ and $r=-0.51, P<0.001$, respectively), a moderate correlation with EF and Ea/Ees $(r=0.26, P<0.001$ and $r=0.29, P<0.001)$ and a weak correlation with LV mass indexed to BSA, EDV indexed to BSA, SV indexed to BSA, CO, Cl, lateral s' wave, LAV, and LAV indexed to BSA, E/e' ratio, GRS , and global circumferential strain (GCS) (Table 3). On multivariable analysis, GCW was significantly correlated with GLS (standardized beta-coefficient $=-0.55$, $P<0.001$ ), SBP (standardized beta-coefficient $=0.71, P<0.001$ ), GRS (standardized beta-coefficient $=0.11, P=0.01$ ) and GCS (standardized beta-coefficient $=-0.10, P=0.02$ ) (Figure 2 and Table 3).

\section{Correlations between GWW and GWE and 2DE parameters}

On multivariable analysis, GWW was significantly correlated with the Tei index (standardized beta-coefficient $=0.17, P=0.01$ ) and inversely correlated with EF (standardized beta-coefficient $=-0.14, P=0.03$ ). The opposite occurred for GWE (standardized beta-coefficient $=-0.20, P=0.004$ and standardized beta-coefficient $=0.18$, $P=0.009$, respectively, Tables 4 and 5).

\section{Discussion}

Reference ranges for $\mathrm{MW}$ indices have been recently provided by the previous NORRE study. ${ }^{24}$ Correlations between MW and demographical variables have been also investigated, showing the absence of a strong dependence of MW indices on age, gender, and body mass index. ${ }^{24}$ Hence, due to the growing interest in $\mathrm{MW}$, the present NORRE sub-study sought to evaluate the correlations existing between the new indices of MW and LV dimensions, standard and advanced 2DE parameters of LV systolic function, and indices of diastolic function.

We did not find a strong correlation between MW indices and LV size. On univariable analysis, GWW and GWE were indeed weakly correlated with ESV, whereas GWI and GCW were weakly correlated with LV mass indexed to BSA. The latter finding could be due to the fact of a major contractile mass being involved in the production of positive work. ${ }^{30}$ However, in pathological cardiac hypertrophy, a reduction of $\mathrm{MW}$ indices was recently reported. ${ }^{31}$ Despite the physiological interest, we have to acknowledge that all these associations are not strong, not observed for all MW indices, and not confirmed in multivariable analysis; so their real clinical significance is doubtful. Probably, these data could be explained when considering that the study population was entirely composed of healthy subjects, leading to restricted LV size values ranges. In cardiac disease, such as cardiomyopathies and heart valve disease, instead, changes in both LV size and function are often observed ${ }^{32-34}$ Thus, LV remodelling and dysfunction are usually strictly correlated, the one affected by 


\section{Table 3 Univariable and multivariable analysis for GCW}

\begin{tabular}{|c|c|c|c|c|}
\hline \multirow[t]{2}{*}{ Variables } & \multicolumn{2}{|l|}{$\begin{array}{l}\text { Univariable } \\
\text { analysis }\end{array}$} & \multicolumn{2}{|l|}{$\begin{array}{l}\text { Multivariable } \\
\text { analysis }\end{array}$} \\
\hline & Coefficient & t $P$ & $\begin{array}{l}\text { Standardized } \\
\beta \text {-coefficient }\end{array}$ & d $P$ \\
\hline $\mathrm{SBP}(\mathrm{mmHg})$ & 0.64 & $<0.001$ & 0.71 & $<0.001$ \\
\hline $\mathrm{EDV}(\mathrm{mL})$ & 0.13 & 0.06 & & \\
\hline $\mathrm{ESV}(\mathrm{mL})$ & -0.01 & 0.8 & & \\
\hline EDV indexed $\left(\mathrm{mL} / \mathrm{m}^{2}\right)$ & 0.14 & 0.04 & & \\
\hline ESV indexed $\left(\mathrm{mL} / \mathrm{m}^{2}\right)$ & -0.02 & 0.6 & & \\
\hline EF (\%) & 0.26 & $<0.001$ & & \\
\hline $\mathrm{LV}$ mass indexed $\left(\mathrm{g} / \mathrm{m}^{2}\right)$ & 0.17 & 0.008 & & \\
\hline $\mathrm{SV}$ indexed, $\mathrm{mL} / \mathrm{m}^{2}$ & 0.25 & $<0.001$ & & \\
\hline $\mathrm{CO}(\mathrm{mL} / \mathrm{min})$ & 0.16 & 0.01 & & \\
\hline $\mathrm{Cl}\left(\mathrm{mL} / \mathrm{min} / \mathrm{m}^{2}\right)$ & 0.19 & 0.005 & & \\
\hline Septal MAPSE (mm) & -0.02 & 0.7 & & \\
\hline Lateral MAPSE (mm) & -0.006 & 0.9 & & \\
\hline Septal s' wave (cm/s) & -0.05 & 0.4 & & \\
\hline Lateral s' wave $(\mathrm{cm} / \mathrm{s})$ & -0.14 & 0.03 & & \\
\hline $\mathrm{LAV}(\mathrm{mL})$ & 0.17 & 0.01 & & \\
\hline LAV indexed $\left(\mathrm{mL} / \mathrm{m}^{2}\right)$ & 0.23 & 0.001 & & \\
\hline E wave $(\mathrm{cm} / \mathrm{s})$ & 0.05 & 0.4 & & \\
\hline A wave $(\mathrm{cm} / \mathrm{s})$ & 0.11 & 0.09 & & \\
\hline Deceleration time (ms) & -0.02 & 0.7 & & \\
\hline E/A ratio & -0.06 & 0.3 & & \\
\hline Septal e' wave $(\mathrm{cm} / \mathrm{s})$ & -0.15 & 0.01 & & \\
\hline Lateral e' wave (cm/s) & -0.07 & 0.2 & & \\
\hline Ele' ratio & 0.2 & 0.003 & & \\
\hline PASP $(\mathrm{mmHg})$ & 0.03 & 0.6 & & \\
\hline Tei index & -0.03 & 0.5 & & \\
\hline $\mathrm{Ea}(\mathrm{mmHg} / \mathrm{mL})$ & 0.08 & 0.2 & & \\
\hline Ees $(\mathrm{mmHg} / \mathrm{mL})$ & 0.08 & 0.2 & & \\
\hline $\mathrm{Ea} / \mathrm{Ees}$ & 0.29 & $<0.001$ & & \\
\hline GLS (\%) & -0.51 & $<0.001$ & -0.55 & $<0.001$ \\
\hline GCS (\%) & -0.16 & 0.04 & -0.10 & 0.02 \\
\hline GRS (\%) & 0.19 & 0.01 & 0.11 & 0.01 \\
\hline
\end{tabular}

$P$-values $<0.05$ are set in bold.

$\mathrm{Cl}$, cardiac index; $\mathrm{CO}$, cardiac output; Ea, arterial elastance; EDV, end-diastolic volume; Ees, end-systolic elastance; EF, ejection fraction; ESV, end-systolic volume; GCS, global circumferential strain; GCW, global constructive work; GLS, global longitudinal strain; GRS, global radial strain; GWE, global work efficiency; GWI, global work index; GWW, global work waste; IQR, interquartile range; LAV, left atrial volume; LV, left ventricle; MAPSE, mitral annular plane systolic excursion; PASP, pulmonary arterial systolic pressure; SD, standard deviation; SBP, systolic blood pressure; SV, stroke volume.

the other and vice versa, especially in advanced cardiovascular diseases. On the contrary, in normal subjects, it is not really surprising to find only a mild association between LV size and indices of MW, being both in a normal range.

Regarding LV systolic function, we tested correlations with traditional parameters and with MS, which is an established advanced index to study LV systolic function. While associations with GLS were obviously expected, we also found an intriguing significant correlation between both GWI and GCW with GRS. Furthermore, GCW was significantly correlated even with GCS. As known, due to the complex architecture of myocardial fibres, the LV systolic motion is the result of three principal components: base to apex longitudinal shortening, epicardium towards endocardium radial thickening and circumferential rotation and shortening. ${ }^{1}$ Our findings, thus, highlights as likely all the components of myocardial deformation contribute to generate MW, so it, and in particular GCW, could be supposed to globally reflect LV mechanics and performance. In our analysis, GWI and GCW were also significantly correlated with parameters that traditionally reflect LV systolic performance, namely EF, SV, CO, and $\mathrm{Cl}$. These data are perfectly in accordance with the physiological substrate of GWI and GCW. In a normal heart, indeed, all myocardial segments contract in a synchronized manner resulting in positive work, the constructive work, which by definition is the work contributing towards LV ejection. ${ }^{12}$ Accordingly, GCW, as index of contractile and viable myocardium, has been proposed as a potential parameter to identify CRT responders by Galli et al. ${ }^{12,13}$ The same authors showed preliminary results of GCW's application even in non-obstructive hypertrophic cardiomyopathy, as a reliable tool to estimate LV performance and functional capacity. ${ }^{31}$

Among diastolic parameters, GWI and GCW correlated with LA size and E/E' ratio, though only on univariable analysis. Probably this finding should be interpreted in the context of normal ranges of both the diastolic parameters. In our population, in fact, increasing values of LA size and E/e' were not an expression of diastolic dysfunction, being both in the normal range. Besides, this association was not confirmed in multivariable analysis; so according to our data correlation of MW with parameters of diastolic function was really poor. However, an interesting exception was the Tei index. A significant association between Tei index and both GWW and GWE was found. It is a combined index of global systolic and diastolic function, which relies on measure of the same part of cardiac cycle analysed by MW: from mitral valve closure to mitral valve opening, namely mechanical systole including isovolumetric relaxation time. Higher values of Tei index are secondary to prolonged IVCT and/or IVRT respect to ET; it could be translated in a higher wasted work, due mainly to myocyte $s$ s shortening in a prolonged IVRT, and consequent lower efficiency.

Finally, as MW has been recently proposed as a potential new method of estimation of VAC, ${ }^{35}$ we aimed to test its correlation with the main index of VAC, Ea/Ees ratio, calculated by echocardiography. ${ }^{29,36}$ It is the result of complex formulas including SV, EF, SBP, and diastolic blood pressure (all parameters correlated with GWI and GCW) and accounting for time too. ${ }^{29}$ So, the significant correlation with Ea/Ees ratio and its easier measurement could reinforce its application also as an alternative index of VAC. However, more studies are needed to evaluate the performance of $\mathrm{MW}$ and its role as an established tool for studying VAC needs to be further investigated and validated.

Our data, hence, support the role of MW as a reliable parameter of myocardial systolic performance, in addition to traditional ones and MS. MW, indeed, adjusting myocardial deformation for LVP dynamics, could offer further information for the evaluation of cardiac performance in conditions of subclinical LV dysfunction as well as in heart failure with preserved EF (HFpEF). In this field preliminary data have been recently obtained, depicting the superiority of GCW respect to GLS as a better determinant of exercise capacity in patients 

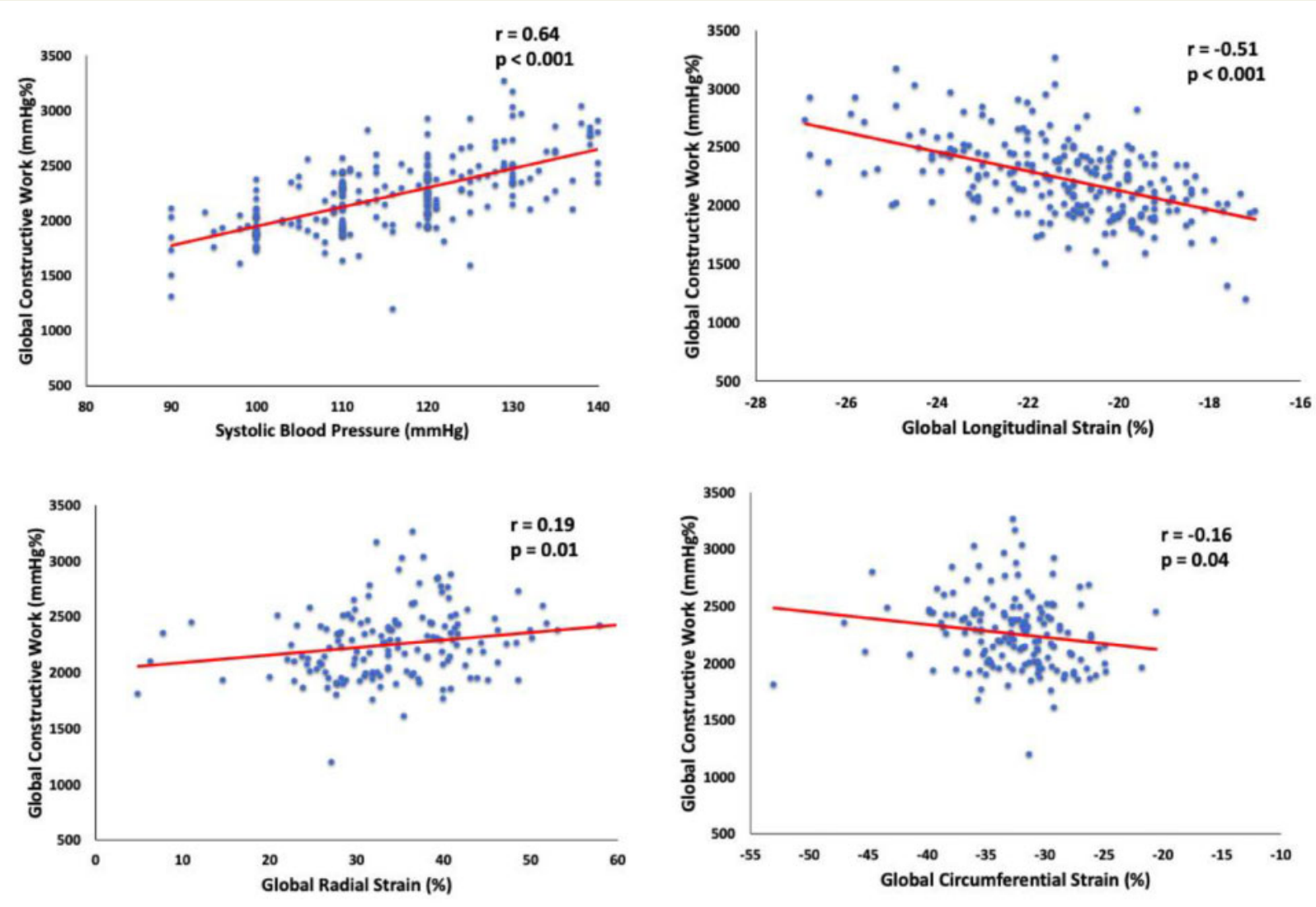

Figure 2 Main relations of global constructive work.

with HFpEF. ${ }^{37}$ Therefore, besides its promising application in patients candidates to CRT, MW could be investigated in the subset of patients at risk of development or at an early stage of cardiovascular disease, for example patients under cardiotoxic treatment.

\section{Limitations}

Only $31 \%$ of the patients included in the NORRE study have been available for MW analysis, due mainly to the possibility of application of MW only to exams acquired through GE echocardiographic ultrasound system, adding the dependency on image quality and blood pressure availability. Moreover, whether the NORRE study results can be extrapolated to non-Caucasian European individuals is still unknown.

Non-invasive LVP estimation by brachial cuff pressure is imprecise, representing a limitation of LV PSLs as obtained by Russell et al. Nevertheless, it was recently demonstrated that, despite discrepancies between cuff pressure and invasive pressure, MW analysis was accurate, due to temporal integration and less pressure differences from aortic valve opening to closure. ${ }^{38}$

Based on our findings the current software is indeed promising, but further studies in larger populations with various forms of heart diseases, comparing the results of this software against

invasively obtained PV loops and calculations of cardiac work parameters, are required before introducing it into daily clinical use.

\section{Conclusion}

The NORRE study shows good correlations of GWI with EF and GRS, and of GCW with GRS and GCS, as well as with GLS. Weak correlations are observed between MW indices and LV size. MW is a promising tool to study myocardial systolic performance; however, further investigations are needed before introducing it in routine clinical practice.

\section{Acknowledgements}

The EACVI Research and Innovation Committee thanks the Heart House for its support.

\section{Funding}

The NORRE Study was supported by the GE Healthcare and Philips Healthcare in the form of an unrestricted educational grant. Sponsor funding has in no way influenced the content or management of this study.

Conflict of interest: none declared.

\section{References}

1. Geyer H, Caracciolo G, Abe H, Wilansky S, Carerj S, Gentile F et al. Assessment of myocardial mechanics using speckle tracking echocardiography: fundamentals and clinical applications. J Am Soc Echocardiogr 2010;23:351-69; quiz 453-5.

2. Mor-Avi V, Lang RM, Badano LP, Belohlavek M, Cardim NM, Derumeaux G et al. Current and evolving echocardiographic techniques for the quantitative evaluation of cardiac mechanics: ASE/EAE consensus statement on methodology and 


\section{Table 4 Univariable and multivariable analysis for GWW}

\begin{tabular}{|c|c|c|c|c|}
\hline \multirow[t]{2}{*}{ Variables } & \multicolumn{2}{|c|}{$\begin{array}{l}\text { Univariable } \\
\text { analysis }\end{array}$} & \multicolumn{2}{|l|}{$\begin{array}{l}\text { Multivariable } \\
\text { analysis }\end{array}$} \\
\hline & Coefficient & $P$ & $\begin{array}{l}\text { Standardized } \\
\beta \text {-coefficient }\end{array}$ & $P$ \\
\hline $\mathrm{SBP}(\mathrm{mmH} g)$ & 0.12 & 0.07 & & \\
\hline $\mathrm{EDV}(\mathrm{mL})$ & 0.04 & 0.5 & & \\
\hline $\mathrm{ESV}(\mathrm{mL})$ & 0.14 & 0.03 & & \\
\hline EDV indexed $\left(\mathrm{mL} / \mathrm{m}^{2}\right)$ & -0.008 & 0.9 & & \\
\hline ESV indexed $\left(\mathrm{mL} / \mathrm{m}^{2}\right)$ & 0.12 & 0.06 & & \\
\hline $\mathrm{EF}(\%)$ & -0.17 & 0.01 & -0.14 & 0.03 \\
\hline $\mathrm{LV}$ mass indexed $\left(\mathrm{g} / \mathrm{m}^{2}\right)$ & 0.03 & 0.6 & & \\
\hline $\mathrm{SV}$ indexed $\left(\mathrm{mL} / \mathrm{m}^{2}\right)$ & 0.05 & 0.4 & & \\
\hline $\mathrm{CO}(\mathrm{mL} / \mathrm{min})$ & 0.04 & 0.5 & & \\
\hline $\mathrm{Cl}\left(\mathrm{mL} / \mathrm{min} / \mathrm{m}^{2}\right)$ & -0.02 & 0.7 & & \\
\hline Septal MAPSE (mm) & 0.01 & 0.8 & & \\
\hline Lateral MAPSE (mm) & -0.01 & 0.8 & & \\
\hline Septal s' wave (cm/s) & -0.08 & 0.2 & & \\
\hline Lateral s' wave (cm/s) & -0.01 & 0.8 & & \\
\hline $\mathrm{LAV}(\mathrm{mL})$ & 0.11 & 0.1 & & \\
\hline LAV indexed $\left(\mathrm{mL} / \mathrm{m}^{2}\right)$ & 0.06 & 0.3 & & \\
\hline E wave $(\mathrm{cm} / \mathrm{s})$ & -0.11 & 0.1 & & \\
\hline A wave $(\mathrm{cm} / \mathrm{s})$ & -0.03 & 0.5 & & \\
\hline Deceleration time (ms) & 0.07 & 0.2 & & \\
\hline E/A ratio & -0.05 & 0.4 & & \\
\hline Septal e' wave $(\mathrm{cm} / \mathrm{s})$ & -0.12 & 0.05 & & \\
\hline Lateral e' wave (cm/s) & -0.07 & 0.9 & & \\
\hline E/e' ratio & -0.03 & 0.6 & & \\
\hline $\mathrm{PASP}(\mathrm{mmHg})$ & -0.04 & 0.6 & & \\
\hline Tei index & 0.24 & $<0.001$ & 0.17 & 0.01 \\
\hline $\mathrm{Ea}(\mathrm{mmHg} / \mathrm{mL})$ & -0.05 & 0.4 & & \\
\hline Ees $(\mathrm{mmH} / \mathrm{mL})$ & -0.05 & 0.4 & & \\
\hline $\mathrm{Ea} /$ Ees & -0.04 & 0.5 & & \\
\hline GLS (\%) & 0.09 & 0.1 & & \\
\hline GCS (\%) & 0.03 & 0.6 & & \\
\hline GRS (\%) & -0.4 & 0.6 & & \\
\hline
\end{tabular}

$P$-values $<0.05$ are set in bold.

$\mathrm{Cl}$, cardiac index; $\mathrm{CO}$, cardiac output; Ea, arterial elastance; EDV, end-diastolic volume; Ees, end-systolic elastance; EF, ejection fraction; ESV, end-systolic volume; GCS, global circumferential strain; GCW, global constructive work; GLS, global longitudinal strain; GRS, global radial strain; GWE, global work efficiency; GWI, global work index; GWW, global work waste; IQR, interquartile range; LAV, left atrial volume; LV, left ventricle; MAPSE, mitral annular plane systolic excursion; PASP, pulmonary arterial systolic pressure; SD, standard deviation; SBP, systolic blood pressure; SV, stroke volume.
Table 5 Univariable and multivariable analysis for GWE

\begin{tabular}{|c|c|c|c|c|}
\hline \multirow[t]{2}{*}{ Variables } & \multicolumn{2}{|l|}{$\begin{array}{l}\text { Univariable } \\
\text { analysis }\end{array}$} & \multicolumn{2}{|l|}{$\begin{array}{l}\text { Multivariable } \\
\text { analysis }\end{array}$} \\
\hline & Coefficient & $P$ & $\begin{array}{l}\text { Standardized } \\
\beta \text {-coefficient }\end{array}$ & $P$ \\
\hline $\mathrm{SBP}(\mathrm{mmHg})$ & 0.004 & 0.9 & & \\
\hline $\mathrm{EDV}(\mathrm{mL})$ & -0.02 & 0.6 & & \\
\hline $\mathrm{ESV}(\mathrm{mL})$ & -0.15 & 0.03 & & \\
\hline EDV indexed $\left(\mathrm{mL} / \mathrm{m}^{2}\right)$ & 0.01 & 0.8 & & \\
\hline ESV indexed $\left(\mathrm{mL} / \mathrm{m}^{2}\right)$ & -0.14 & 0.04 & & \\
\hline $\mathrm{EF}(\%)$ & 0.20 & 0.004 & 0.18 & 0.009 \\
\hline LV mass indexed $\left(\mathrm{g} / \mathrm{m}^{2}\right)$ & 0.01 & 0.8 & & \\
\hline $\mathrm{SV}$ indexed $\left(\mathrm{mL} / \mathrm{m}^{2}\right)$ & -0.03 & 0.6 & & \\
\hline $\mathrm{CO}(\mathrm{mL} / \mathrm{min})$ & -0.02 & 0.7 & & \\
\hline $\mathrm{Cl}\left(\mathrm{mL} / \mathrm{min} / \mathrm{m}^{2}\right)$ & 0.03 & 0.6 & & \\
\hline Septal MAPSE (mm) & 0.009 & 0.9 & & \\
\hline Lateral MAPSE $(\mathrm{mm})$ & 0.02 & 0.7 & & \\
\hline Septal s' wave $(\mathrm{cm} / \mathrm{s})$ & 0.08 & 0.2 & & \\
\hline Lateral s' wave $(\mathrm{cm} / \mathrm{s})$ & -0.008 & 0.9 & & \\
\hline $\mathrm{LAV}(\mathrm{mL})$ & -0.07 & 0.3 & & \\
\hline LAV indexed $\left(\mathrm{mL} / \mathrm{m}^{2}\right)$ & -0.02 & 0.7 & & \\
\hline E wave $(\mathrm{cm} / \mathrm{s})$ & 0.11 & 0.9 & & \\
\hline A wave $(\mathrm{cm} / \mathrm{s})$ & 0.02 & 0.7 & & \\
\hline Deceleration time (ms) & -0.09 & 0.1 & & \\
\hline E/A ratio & 0.05 & 0.4 & & \\
\hline Septal e' wave $(\mathrm{cm} / \mathrm{s})$ & 0.12 & 0.07 & & \\
\hline Lateral e' wave $(\mathrm{cm} / \mathrm{s})$ & 0.03 & 0.6 & & \\
\hline E/e' ratio & 0.02 & 0.7 & & \\
\hline PASP $(\mathrm{mmHg})$ & 0.03 & 0.7 & & \\
\hline Tei index & -0.26 & $<0.0001$ & -0.20 & 0.004 \\
\hline $\mathrm{Ea}(\mathrm{mmHg} / \mathrm{mL})$ & 0.07 & 0.2 & & \\
\hline Ees $(\mathrm{mmH} / \mathrm{mL})$ & 0.07 & 0.3 & & \\
\hline $\mathrm{Ea} /$ Ees & 0.08 & 0.2 & & \\
\hline GLS (\%) & -0.019 & 0.003 & & \\
\hline GCS (\%) & -0.06 & 0.4 & & \\
\hline GRS (\%) & 0.06 & 0.4 & & \\
\hline
\end{tabular}

$P$-values $<0.05$ are set in bold.

$\mathrm{Cl}$, cardiac index; $\mathrm{CO}$, cardiac output; Ea, arterial elastance; EDV, end-diastolic volume; Ees, end-systolic elastance; EF, ejection fraction; ESV, end-systolic volume; GCS, global circumferential strain; GCW, global constructive work; GLS, global longitudinal strain; GRS, global radial strain; GWE, global work efficiency; GWI, global work index; GWW, global work waste; IQR, interquartile range; LAV, left atrial volume; LV, left ventricle; MAPSE, mitral annular plane systolic excursion; PASP, pulmonary arterial systolic pressure; SD, standard deviation; SBP, systolic blood pressure; SV, stroke volume. indications endorsed by the Japanese Society of Echocardiography. Eur J Echocardiogr 2011;12:167-205.

3. Di Bella G, Minutoli F, Pingitore A, Zito C, Mazzeo A, Aquaro GD et al. Endocardial and epicardial deformations in cardiac amyloidosis and hypertrophic cardiomyopathy. Circ J 2011;75:1200-8.

4. Zito C, Manganaro R, Khandheria B, Oreto G, Cusma-Piccione M, Todaro MC et al. Usefulness of left atrial reservoir size and left ventricular untwisting rate for predicting outcome in primary mitral regurgitation. Am J Cardiol 2015;116:1237-44.

5. Plana JC, Galderisi M, Barac A, Ewer MS, Ky B, Scherrer-Crosbie M et al. Expert consensus for multimodality imaging evaluation of adult patients during and after cancer therapy: a report from the American Society of Echocardiography and the European Association of Cardiovascular Imaging. Eur Heart J Cardiovasc Imaging 2014;15:1063-93.

6. Donal E, Thebault C, O'Connor K, Veillard D, Rosca M, Pierard L et al. Impact of aortic stenosis on longitudinal myocardial deformation during exercise. Eur J Echocardiogr 2011;12:235-41.

7. Dulgheru R, Magne J, Davin L, Nchimi A, Oury C, Pierard LA et al. Left ventricular regional function and maximal exercise capacity in aortic stenosis. Eur Heart J Cardiovasc Imaging 2016;17:217-24.

8. Galli E, Lancellotti P, Sengupta PP, Donal E. LV mechanics in mitral and aortic valve diseases: value of functional assessment beyond ejection fraction. JACC Cardiovasc Imaging 2014;7:1151-66. 
9. Lancellotti P, Donal E, Magne J, O'Connor K, Moonen ML, Cosyns B et al. Impact of global left ventricular afterload on left ventricular function in asymptomatic severe aortic stenosis: a two-dimensional speckle-tracking study. Eur J Echocardiogr 2010;11:537-43.

10. Russell K, Eriksen M, Aaberge L, Wilhelmsen N, Skulstad H, Remme EW et al. A novel clinical method for quantification of regional left ventricular pressurestrain loop area: a non-invasive index of myocardial work. Eur Heart J 2012;33: 724-33.

11. Boe E, Russell K, Eek C, Eriksen M, Remme EW, Smiseth OA et al. Non-invasive myocardial work index identifies acute coronary occlusion in patients with nonST-segment elevation-acute coronary syndrome. Eur Heart J Cardiovasc Imaging 2015;16:1247-55.

12. Galli E, Leclercq C, Fournet M, Hubert A, Bernard A, Smiseth OA et al. Value of myocardial work estimation in the prediction of response to cardiac resynchronization therapy. J Am Soc Echocardiogr 2018;31:220-30.

13. Galli E, Leclercq C, Hubert A, Bernard A, Smiseth OA, Mabo P et al. Role of myocardial constructive work in the identification of responders to CRT. Eur Heart J Cardiovasc Imaging 2018;19:1010-8.

14. Russell K, Eriksen M, Aaberge L, Wilhelmsen N, Skulstad H, Gjesdal O et al. Assessment of wasted myocardial work: a novel method to quantify energy loss due to uncoordinated left ventricular contractions. Am J Physiol Heart Circ Physiol 2013;305:H996-1003.

15. Chan J, Edwards NFA, Khandheria BK, Shiino K, Sabapathy S, Anderson B et al. A new approach to assess myocardial work by non-invasive left ventricular pressure-strain relations in hypertension and dilated cardiomyopathy. Eur Heart J Cardiovasc Imaging 2019;20:31-9.

16. Galli E, Hubert A, Le Rolle V, Hernandez A, Smiseth OA, Mabo P et al. Myocardial constructive work and cardiac mortality in resynchronization therapy candidates. Am Heart J 2019;212:53-63.

17. Edwards NFA, Scalia GM, Shiino K, Sabapathy S, Anderson B, Chamberlain R et al. Global myocardial work is superior to global longitudinal strain to predict significant coronary artery disease in patients with normal left ventricular function and wall motion. J Am Soc Echocardiogr 2019;doi:10.1016/j.echo.2019.02.014.

18. Kou S, Caballero L, Dulgheru R, Voilliot D, De Sousa C, Kacharava G et al. Echocardiographic reference ranges for normal cardiac chamber size: results from the NORRE study. Eur Heart J Cardiovasc Imaging 2014;15:680-90.

19. Caballero L, Kou S, Dulgheru R, Gonjilashvili N, Athanassopoulos GD, Barone D et al. Echocardiographic reference ranges for normal cardiac Doppler data: results from the NORRE Study. Eur Heart J Cardiovasc Imaging 2015;16:1031-41.

20. Saura D, Dulgheru R, Caballero L, Bernard A, Kou S, Gonjilashvili N et al. Twodimensional transthoracic echocardiographic normal reference ranges for proximal aorta dimensions: results from the EACVI NORRE study. Eur Heart J Cardiovasc Imaging 2017; 18:167-79.

21. Bernard A, Addetia K, Dulgheru R, Caballero L, Sugimoto T, Akhaladze N et al. 3D echocardiographic reference ranges for normal left ventricular volumes and strain: results from the EACVI NORRE study. Eur Heart J Cardiovasc Imaging 2017; 18:475-83.

22. Sugimoto T, Dulgheru R, Bernard A, llardi F, Contu L, Addetia K et al. Echocardiographic reference ranges for normal left ventricular 2D strain: results from the EACVI NORRE study. Eur Heart J Cardiovasc Imaging 2017;18:833-40.

23. Sugimoto $T$, Robinet $S$, Dulgheru R, Bernard A, llardi F, Contu L et al. Echocardiographic reference ranges for normal left atrial function parameters: results from the EACVI NORRE study. Eur Heart J Cardiovasc Imaging 2018;19: 630-8.
24. Manganaro R, Marchetta S, Dulgheru R, llardi F, Sugimoto T, Robinet S et al. Echocardiographic reference ranges for normal non-invasive myocardial work indices: results from the EACVI NORRE study. Eur Heart J Cardiovasc Imaging 2019; 20:582-90.

25. Lancellotti P, Badano LP, Lang RM, Akhaladze N, Athanassopoulos GD, Barone $\mathrm{D}$ et al. Normal reference ranges for echocardiography: rationale, study design, and methodology (NORRE Study). Eur Heart J Cardiovasc Imaging 2013;14:303-8.

26. Cosyns B, Garbi M, Separovic J, Pasquet A, Lancellotti P. Update of the echocardiography core syllabus of the European Association of Cardiovascular Imaging (EACVI). Eur Heart J Cardiovasc Imaging 2013;14:837-9.

27. Lang RM, Badano LP, Mor-Avi V, Afilalo J, Armstrong A, Ernande L et al. Recommendations for cardiac chamber quantification by echocardiography in adults: an update from the American Society of Echocardiography and the European Association of Cardiovascular Imaging. J Am Soc Echocardiogr 2015;28: 1-39.e14.

28. Tei C, Ling LH, Hodge DO, Bailey KR, Oh JK, Rodeheffer RJ et al. New index of combined systolic and diastolic myocardial performance: a simple and reproducible measure of cardiac function-a study in normals and dilated cardiomyopathy. J Cardiol 1995;26:357-66.

29. Chen CH, Fetics B, Nevo E, Rochitte CE, Chiou KR, Ding PA et al. Noninvasive single-beat determination of left ventricular end-systolic elastance in humans. J Am Coll Cardiol 2001;38:2028-34.

30. Sonnenblick EH. Correlation of myocardial ultrastructure and function. Circulation 1968;38:29-44.

31. Galli E, Vitel E, Schnell F, Le Rolle V, Hubert A, Lederlin M et al. Myocardial constructive work is impaired in hypertrophic cardiomyopathy and predicts left ventricular fibrosis. Echocardiography 2019;36:74-82.

32. Dulgheru R, Pibarot P, Sengupta PP, Pierard LA, Rosenhek R, Magne J et al. Multimodality Imaging Strategies for the Assessment of Aortic Stenosis: viewpoint of the Heart Valve Clinic International Database (HAVEC) Group. Circ Cardiovasc Imaging 2016;9:e004352.

33. Zito C, Cusma-Piccione M, Oreto L, Tripepi S, Mohammed M, Di Bella G et al. In patients with post-infarction left ventricular dysfunction, how does impaired basal rotation affect chronic ischemic mitral regurgitation? J Am Soc Echocardiogr 2013;26:1118-29.

34. Narayan HK, Finkelman B, French B, Plappert T, Hyman D, Smith AM et al. Detailed echocardiographic phenotyping in breast cancer patients: associations with ejection fraction decline, recovery, and heart failure symptoms over 3 years of follow-up. Circulation 2017;135:1397-412.

35. Ikonomidis I, Aboyans V, Blacher J, Brodmann M, Brutsaert DL, Chirinos JA et al. The role of ventricular-arterial coupling in cardiac disease and heart failure: assessment, clinical implications and therapeutic interventions. A consensus document of the European Society of Cardiology Working Group on Aorta \& Peripheral Vascular Diseases, European Association of Cardiovascular Imaging, and Heart Failure Association. Eur J Heart Fail 2019;21:402-24.

36. Suga $H$, Sagawa K. Instantaneous pressure-volume relationships and their ratio in the excised, supported canine left ventricle. Circ Res 1974;35:117-26.

37. Mysiak A, Kosowski W, Przewlocka-Kosmala M, Kosmala W, Marwick TH. Usefulness of myocardial work measurement in the assessment of left ventricular systolic reserve response to spironolactone in heart failure with preserved ejection fraction. Eur Heart J Cardiovasc Imaging 2019;doi:10.1093/ehjci/jez027.

38. Hubert A, Le Rolle V, Leclercq C, Galli E, Samset E, Casset C et al. Estimation of myocardial work from pressure-strain loops analysis: an experimental evaluation. Eur Heart J Cardiovasc Imaging 2018;19:1372-9. 